\title{
Plasma amino acid concentrations in parenterally fed preterm infants
}

\author{
D CLARK, M HENDERSON,${ }^{*}$ M SMITH, ${ }^{*}$ AND P R F DEAR \\ Department of Paediatrics and Child Health and *Department of Chemical Pathology, St James's University \\ Hospital, Leeds
}

SUMMARY One hundred and nine sick preterm infants were studied, and the data obtained show that hyperphenylalaninaemia is an extremely rare occurrence as long as an adequate source of energy is provided. High concentrations of the other aromatic amino acid (tyrosine) on the other hand, were often encountered and seem to be due to immaturity of an isolated hepatic enzyme as there was no correlation between phenylalanine and tyrosine concentrations. Possible adverse consequences of hypertyrosinaemia are discussed in relation to toxicity and the assessment of hepatic function. We provide reference centiles for plasma amino acid concentrations in this population.

Medical opinion concerning the exact indications for parenteral nutrition in the newborn is far from uniform and its formation is hampered by the lack of prospective randomised trials comparing parenteral with enteral feeding. ${ }^{1-5}$ Nevertheless it has been shown that a satisfactory rate of weight gain can be achieved with parenteral nutrition, ${ }^{5}$ and it continues to be used regularly in the care of ill newborn babies, especially during intensive care of the very low birthweight baby, and after surgery. Many complications of parenteral nutrition have been documented, some relating to the procedure (such as infection of the infusion line), others concerning the requirements and tolerance of nutrients. Recently concern has been expressed about the amino acid content of one of the most commonly used amino acid solutions, Vamin 9 glucose (KabiVitrum). A series of letters to the Lancet $^{6-9}$ reported plasma concentrations of phenylalanine in some parenterally fed newborn babies that were well above the upper limit of $600 \mu \mathrm{mol} / \mathrm{l}$ recommended in the management of phenylketonuria. ${ }^{10}$ These reports are clearly important in alerting users of Vamin 9 glucose to the possibility of achieving potentially toxic phenylalanine concentrations, and hence of the desirability of monitoring plasma concentrations, but they may not be sufficient justification for changing to other amino acid mixtures in search of lower phenylalanine intakes. Each of the competing products on the market has a unique amino acid profile, and it is quite possible that in removing one apparent problem another might be substituted. Also, of the few controlled trials of parenteral nutrition that have been made, most have used Vamin 9 glucose and so there is relatively less information on the clinical effectiveness of other amino acid solutions in the low birthweight baby.

This study was carried out partly to try to confirm our impression that we had not observed the high plasma phenylalanine concentrations being reported from other centres, and partly to generate reference data for plasma amino acid concentrations in a group of parenterally fed very low birthweight babies. We believed that there was every reason to do the latter because there is relatively little reference data on such babies that has been obtained by quantitative analysis.

\section{Patients and methods}

The data were obtained from 109 very low birthweight babies receiving parenteral nutrition as part of intensive care for the problems of prematurity. The mean birth weight was $1277 \mathrm{~g}$ (range 488-1454) and the mean gestational age was 29 weeks (range 23-42). Parenteral nutrition was started on the second or third day of life with $0.5 \mathrm{~g} / \mathrm{kg} /$ day of Intralipid $20 \%$ (KabiVitrum), $0.5 \mathrm{~g} / \mathrm{kg} /$ day of Vamin 9 glucose and $10 \%$ dextrose, plus minerals, electrolytes, and vitamins. In the absence of contraindications (such as severe jaundice or sepsis) fat and amino acid intakes were increased daily by $0.5 \mathrm{~g} / \mathrm{kg} / \mathrm{day}$, to a maximum of $3.0 \mathrm{~g} / \mathrm{kg} /$ day of amino acid, and $4.0 \mathrm{~g} / \mathrm{kg} /$ day of fat. Both fat and amino acids were 
infused continuously throughout each 24 hours. The plasma was screened daily for lipaemia. The plasma triglyceride concentration was monitored weekly on blood taken during the course of the lipid infusion. The concentration was always below $2.0 \mathrm{mmol} / \mathrm{l}$, and usually below $1.5 \mathrm{mmol} / \mathrm{l}$. The intake of $10 \%$ dextrose was gradually increased according to the estimated fluid requirements and carbohydrate tolerance, usually up to a maximum of $180 \mathrm{ml} / \mathrm{kg} /$ day. At the maximum, the energy intake was about $0.502 \mathrm{MJ} / \mathrm{kg} /$ day; an energy:amino acid ratio of $0 \cdot 167 \mathrm{MJ} / \mathrm{g}$. Plasma amino acid profiles were obtained at weekly intervals so that for most babies studied data are available at different postnatal ages and nutrient intakes. For each amino acid profile $0.3 \mathrm{ml}$ of blood was sampled.

Amino acid analysis was carried out on a Hilger Chromaspeck automated ion exchange amino acid analyser. The biochemistry department participates in the external quality control system (NEQUAS) operated by the Wolfson Research Laboratory, Queen Elizabeth Medical Centre, Birmingham. Statistical analysis was performed using Oxstat (Medstat Ltd).

\section{Results}

The table shows the 10th, 50th, and 90th centiles for the plasma concentrations of each amino acid.

To see how plasma amino acid concentrations correlated with gestational age, body weight, and postnatal age, four amino acids were selected-

Table Plasma amino acid concentrations (umol/l) by centile (315 observations were made in 109 babies)

\begin{tabular}{|c|c|c|c|}
\hline \multirow[t]{2}{*}{ Amino acid } & \multicolumn{3}{|c|}{ Centile } \\
\hline & 10 & 50 & 90 \\
\hline Aspartic acid & 32 & 65 & 106 \\
\hline Threonine & 103 & 177 & 306 \\
\hline Serine & 183 & 301 & 458 \\
\hline Glutamic acid & 110 & 220 & 376 \\
\hline Glutamine & 321 & 517 & 780 \\
\hline Glycine & 243 & 358 & 519 \\
\hline Alanine & 186 & 276 & 472 \\
\hline Cystine & 19 & 44 & 75 \\
\hline Valine & 129 & 218 & 300 \\
\hline Methionine & 17 & 32 & .51 \\
\hline Isoleucine & 30 & 68 & 96 \\
\hline Leucine & 64 & 107 & 150 \\
\hline Tyrosine & 75 & 145 & 656 \\
\hline Phenylalanine & 78 & 146 & 266 \\
\hline Histidine & 65 & 95 & 131 \\
\hline Ornithine & 68 & 122 & 208 \\
\hline Lysine & 84 & 166 & 291 \\
\hline Arginine & 5 & 24 & 58 \\
\hline Proline & 181 & 330 & 595 \\
\hline
\end{tabular}

phenylalanine, tyrosine, glycine, and cystine. No significant overall correlations were found in any case, by either parametric (Student's $t$ ) or by nonparametric (Spearmans rank) tests.

The only significant associations were between the plasma concentration of serine, glutamine, cystine, valine, methionine, isoleucine, leucine, and phenylalanine and the total amino acid intake, such that the concentrations were slightly higher at a dose of $3 \mathrm{~g} / \mathrm{kg} /$ day than at $1 \mathrm{~g} / \mathrm{kg} / \mathrm{day}$, and between phenylalanine concentrations and postnatal age, such that the mean concentration rose from $100 \mu \mathrm{mol} / \mathrm{l}$ at 2 days to $187 \mu \mathrm{mol} / \mathrm{l}$ at 10 days (Spearman rank correlation, $\mathrm{p}<0.001$ ).

Fig 1 shows the frequency distribution of plasma phenylalanine concentrations; only four values fell above $500 \mu \mathrm{mol} / \mathrm{l}$, and only two values above $600 \mu \mathrm{mol} / 1$. Fig 2 shows the frequency distribution of plasma tyrosine concentrations. Fig 3 shows the association between plasma phenylalanine and tyrosine concentrations sampled simultaneously. It illustrates clearly the lack of correlation between plasma phenylalanine and tyrosine concentrations, which

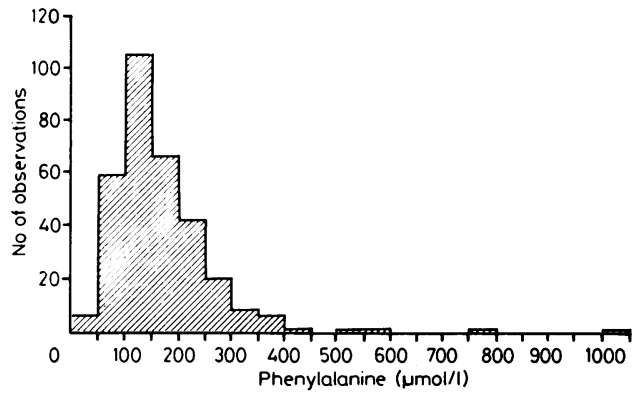

Fig 1 Frequency distribution of plasma phenylalanine concentrations.

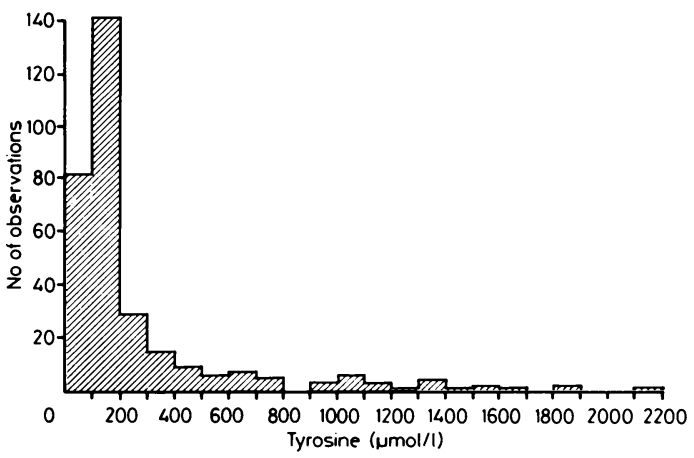

Fig 2 Frequency distribution of plasma tyrosine concentrations. 


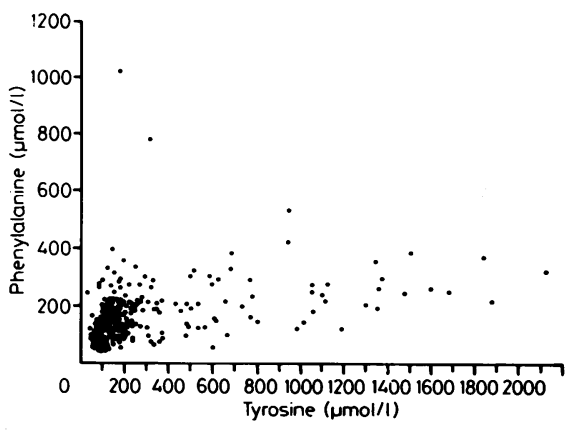

Fig 3 Association between plasma tyrosine and phenylalanine concentrations sampled simultaneously.

suggests immaturity of an enzyme specifically concerned with tyrosine metabolism rather than a generalised hepatocellular immaturity.

\section{Discussion}

In contrast to several recent reports ${ }^{6-9}$ high concentrations of phenylalanine were rarely encountered among this cohort of very low birthweight babies; on only two occasions out of $\mathbf{3 1 5}$ measurements was a plasma phenylalanine concentration greater than $600 \mu \mathrm{mol} / 1$ encountered (fig 1 ). These high concentrations were both detected in the same baby, who does not have any persisting disorder of amino acid metabolism. Many of the babies whom we studied were undoubtedly ill and were predictably in a catabolic state when their amino acid profile was measured. We have no ready explanation for the variance of our findings with those of other authors, but from our large pool of data, analysed with strict attention to quality control, we are confident in concluding that - when used in combination with an adequate source of non-protein energy-Vamin 9 glucose is a satisfactory source of phenylalanine for the parenterally fed very low birthweight baby.

None of the studies that has reported raised phenylalanine concentrations ${ }^{6-9}$ contained information about energy intake, which might be important in explaining the difference between our findings and theirs. Also in some of the studies amino acid values were obtained by thin layer chromatography, which is less accurate than the ion exchange chromatography method that we used. In the light of these studies, however, we would advise that whenever possible total parenteral nutrition should be monitored by the weekly measurement of plasma amino acid concentrations.

Plasma tyrosine concentrations, on the other hand, were often far higher than those regarded as normal in other age groups, including fetal life, ${ }^{11}$ and it is well known that preterm babies show limited tolerance to tyrosine because of impaired p-hydroxyphenylpyruvic acid oxidase activity in the immature liver. It is commonly held that high tyrosine concentrations are not harmful, but published reports leave enough room for doubt ${ }^{12}{ }^{13}$ for it to be prudent to respond to high concentrations by reducing amino acid intake. Interestingly, in the formulation of Vamin specifically for infants, namely 'Vamin Infant' (KabiVitrum), there is a reduced phenylalanine content, but the tyrosine content is unchanged.

The poor tolerance of tyrosine exhibited by the very low birthweight infants in this study has implications for the usefulness of the ratio of the plasma concentrations of branched chain amino acids (leucine, isoleucine, and valine) to those of the aromatic amino acids (phenylalanine and tyrosine) as an index of hepatocellular function in this age group. This test is proving to be useful ${ }^{14} 15$, and the mechanism is as follows: when hepatocytes begin to lose their ability to generate glucose from glycogen for the use of peripheral tissues, the branched chain amino acids are taken up from the plasma as a substitute energy source. At the same time, the failing hepatocytes are less able to metabolise aromatic amino acids, and so the ratio of branched chain to aromatic amino acids in the plasma decreases. Evidence for the clinical usefulness of this ratio is derived mainly from adult studies, but it has been suggested that it may be relevant in the newborn. ${ }^{16}$ We would urge caution in the interpretation of this ratio in the parenterally fed preterm baby because of the high frequency of increased tyrosine concentrations. In $\mathbf{9 2 \%}$ of our observations the ratio was less than 2 , which is the value said to be characteristic of liver failure in the adult. The increases in plasma tyrosine which we have documented almost certainly result from isolated hepatic enzyme immaturity rather than generalised hepatocellular immaturity, as evidenced by the absence of a significant correlation between plasma concentrations of tyrosine and phenylalanine (fig 3).

The data presented in table 1 provide reference ranges for plasma amino acids in the group that we have described when they were fed Vamin 9 glucose continuously throughout each 24 hours. It can be used as a basis for comparison with other groups and with other nutritional regimens. The absence of any overall correlation between plasma amino acid concentrations and any of the variables that we might have expected to influence them is presumably the result of homoeostatic mechanisms. It has the benefit of allowing the production of reference ranges free of qualifications. 
We thank Dr R Jones for his invaluable help with the statistical analysis.

\section{References}

${ }^{1}$ Brans YW, Sumners JE, Dweck HS, Cassady G. Feeding the low birthweight infant: orally or parenterally? Preliminary results of a comparative study. Pediatrics 1974;54:15-22.

2 Glass EJ, Hume R, Lang MA, Forfar JO. Parenteral nutrition compared with transpyloric feeding. Arch Dis Child 1984;59: 131-5.

${ }^{3}$ Gunn T, Reaman G, Outerbridge EW, Colle E. Peripheral total parenteral nutrition for premature infants with respiratory distress syndrome: a controlled study. J Pediatr 1978;92:608-13.

4 Yu VYH, James B, Hendry P, MacMahon RA. Total parenteral nutrition in very low birthweight infants: a controlled trial. Arch Dis Child 1979;54:653-61.

5 Brans YW, Sumners JE, Dweck HS, Bailey PE, Cassady G. Feeding the low birthweight infant: orally or parenterally? Corrected bromide space in parenterally supplemented infants. Pediatrics 1976;58:809-15.

6 Bjorkman $\mathrm{O}$, Lindholm M. Phenylalanine content and total parenteral nutrition. Lancet 1987;i:1311.

7 Puntis JWL, Edwards MA, Green A, Morgan I, Booth IW, Ball PA. Hyperphenylalaninaemia in parenterally fed newborn babies. Lancet 1986;i:1105-6.

8 Walker V, Hall MA, Bulusu S, Allan A. Hyperphenylalaninaemia in parenterally fed newborn babies. Lancet 1986;ii: 1284 .
9 Evans SJ, Wynne-Williams TCJE, Russel CA, Fairbrother A. Hyperphenylalaninaemia in parenterally fed preterm babies. Lancet 1986;ii:1405-6.

10 Tourian AY, Sidbury JB. Phenylketonuria. In: Stanbury JB, Wyndaarden JB, Fredrickson DA, eds. The metabolic basis of inherited disease. New York: McGraw Hill, 1982.

11 McIntosh N, Rodeck CH, Heath R. Plasma amino acids of the mid-trimester human fetus. Biol Neonate 1984;45:218-24.

12 Mamunes P, Prince PE, Thornton NH, Hunt PA, Hitchcock ES Intellectual deficits after transient tyrosinaemia in the term neonate. Pediatrics 1976;57:675-80.

13 Stoerner JW, Butler IJ, Morriss FH, et al. CSF neurotransmitter studies: an infant with ascorbic acid-responsive tyrosinaemia. Am J Dis Child 1980;134:492-4.

14 Rosen HM, Yoshimura N, Hodgman JM. Plasma amino acid patterns in hepatic encephalopathies of differing aetiology. Gastroenterology 1977;72:483-7.

15 Reilly JJ, Halow GM, Gerhardt AL, Ritter PS, Gavaler JS, Van Thiel D. Plasma amino acids in liver transplanation: corrrelation with clinical outcome. Surgery 1985;97:263-9.

16 Glasgow JFT, Moore R. Plasma amino acid ratio as an index of hepatocellular maturity in the neonate. Biol Neonate 1983;44: 146-52.

Correspondence to Dr PRF Dear, Department of Paediatrics and Child Health, St James's University Hospital, Leeds LS9 7TF.

Accepted 8 March 1989 